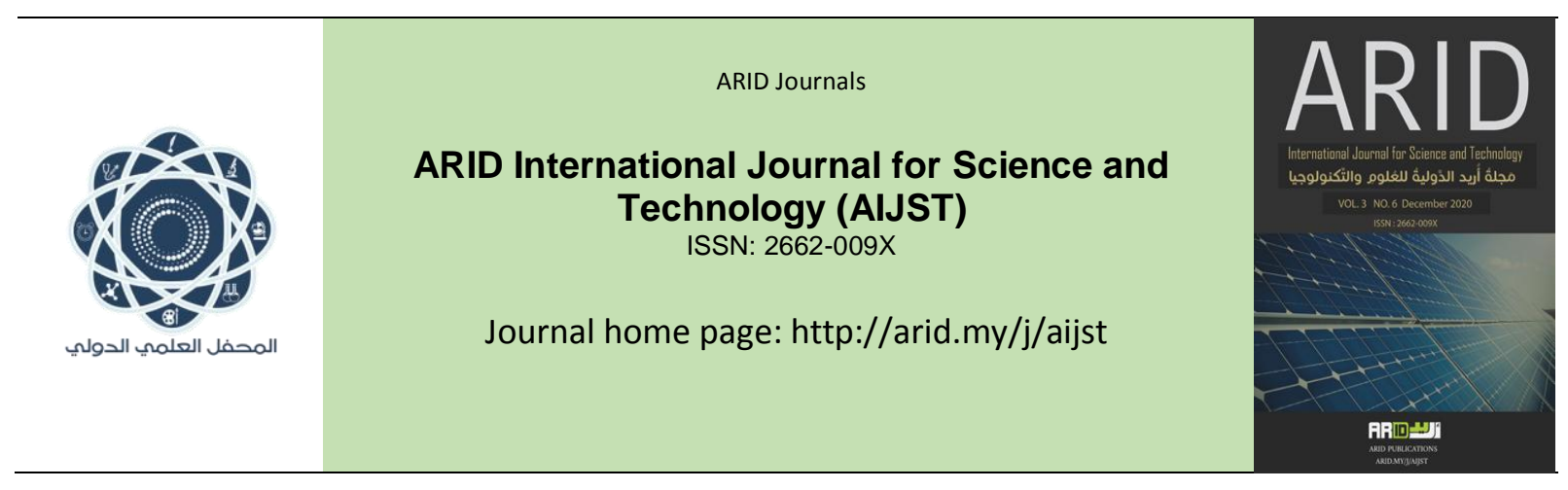

$$
\begin{aligned}
& \text { مَجلةُ أُريد الدَّوليةُ للعُلورِ والتِّكنولوجيا } \\
& \text { العدد } 6 \text { ، البجلد } 3 \text { ، كانون الأول } 2020 \text { م }
\end{aligned}
$$

\title{
Environmental and genetic interaction of some Oat genotypes under the influence of different types of irrigation water
}

التداخل البيئي والوراثي في بعض الطرز الوراثية من الثوفان تحت تأثير نوعيات مختلفة من مياه الري

$$
\text { يوسف عبد الحميد الحاجوج }
$$

$$
\text { كلية الزر اعة-جامعة تكريت العراق }
$$

\section{Ahmed75hawas@tu.edu.iq}




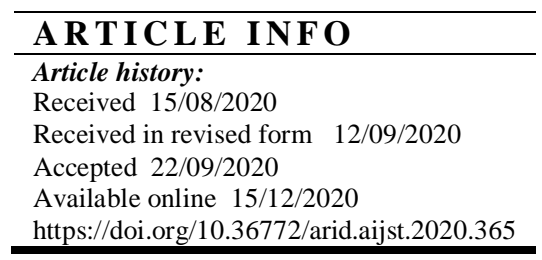

\begin{abstract}
In this study, ten oat genotypes (Alguda , Anatolia , Pimula ,Genzania ,Hamel ,Icarda short ,Kangaroo ,Icarda tall ,Mitika and Possum) were used under the impact of three irrigation water types and two agricultural seasons. Performance and genetic and environmental interaction were studied according to Eberhart and Russel and cluster analysis for Days to anthesis, plant height ,flag leaf area,no.effective tillers , no.grains.panicul , 1000 grains weight and grain yield $\left(\right.$ t.he $\left.{ }^{-1}\right)$, We reached the most important results that was through obtaining statistically significant in analysis of variance table of the sources of difference in environments, genotypes and the interaction between them for all characteristics under study. Genotype (6) distinguished in no.effective tillers (141.06 tiller. $\left.\mathrm{m}^{-2}\right)$, no.grains.panicul ${ }^{-1}$ (66.89 grain.panicul $\left.{ }^{-1}\right)$ and grain yield (1.48 t.he $\mathrm{t}^{-1}$ ) and genotype (1) in days to anthesis (110.70 day) and no.effective tillers (136.67 tiller. $\mathrm{m}^{-2}$ ) and the interaction between fourth environment and genotype (6) for no.grains.panicul (66.67 grains,panicul ${ }^{-1}$ ).In addition to this uniqueness in performance, genotype (6) proved its stability for plant height, 1000 grains weight and grain yield (t.he $\left.{ }^{-1}\right)$. These indices are feasible with evidence that they coincided with yield and some of its components, as well as to high stability to be implemented in future after testing with other factors. In addition to that, obtaining the state of the genetic distance between genotypes tested across environments, in particular genotype (8) with genotypes (6 and 7) and hence can be used in breeding programs, especially hybridization.
\end{abstract}

Key wards: Oat, Stability, Cluster Analysis. 


\section{الملخص}

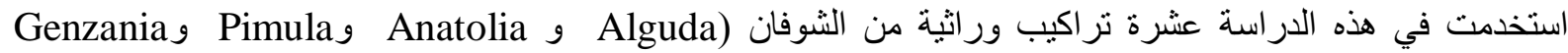

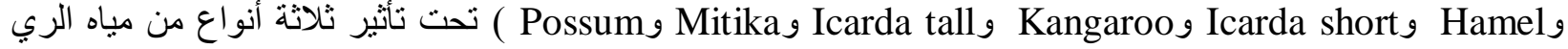

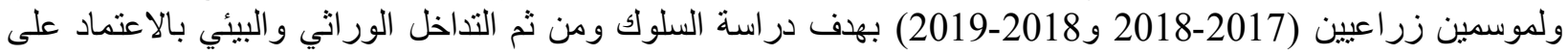

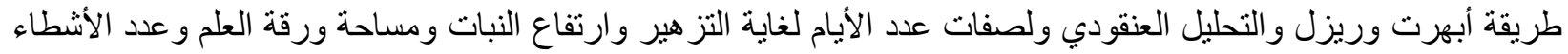

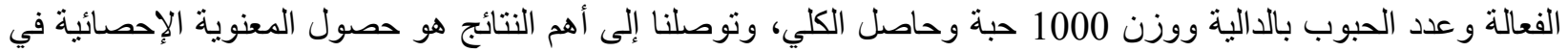

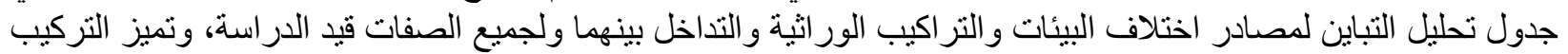

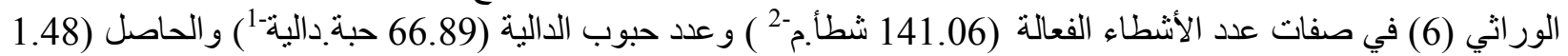

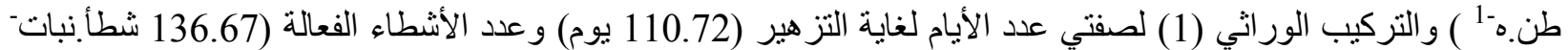

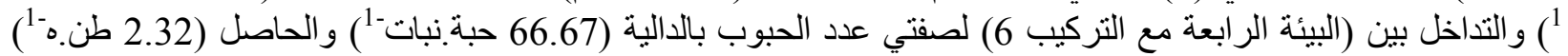

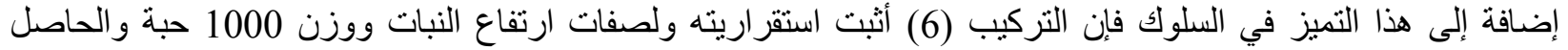

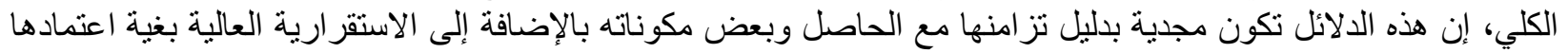

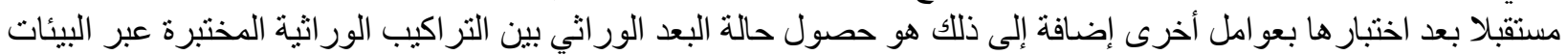
خصوصا التركيب (8) مع التركيبين (6 و7) وبالتالي يمكن الاستفادة منها في بر امج التربية التربية المستقبلية لاسيما التهجين. الكلمات المفتاحية: الثوفان، الاستقرارية، التحليل العنقودي. 


\section{1}

الشوفان Avena sativa Laceae محصول حولي شتوي ينتمي إلى العائلة النجيلية يزرع في الكثير من دول العالم وفي مقدتها أمريكا الثمالية وغرب أوربا. ومن أكثر الدول إنتاجاً لهذا المحصول هي روسيا والولايات المتحدة الأمريكية وكندا وأستر اليا [1]. وبشكل عام يحتوي الـ 100 غرام حبوب من الثوفان على (15.89\%) بروتين و (65.27\%) كاربو هيدرات و (10.61\%) ألياف و(6.2 \%) دهون و 1.78 \%) رماد وغني بالمعادن الهامة والنادرة [2] ـ إن حاجة الإنسان من السعرات الحرارية تبلغ 60\% مصدر ها محاصيل الحبوب، فضلاً عن ذلك تبرز أهميته في كونه يحوي مضاد الأكسدة(Antioxidant) الغني بـ B-glucan وهي ألياف بروتينية غذائية قابلة للذوبان ترتبط بقوة بالكولسترول لتخفض مستوياته وتعزز صحة القلب و علاج مرض السكري [3]. إن الحاجة لهذا المحصول في تزايد مستمر كمصول ثنائي الغرض للحبوب و العلف بل وطبياً، وماز ال هذا المحصول في العراق غبر منتشر ومقتصر على مستوى الدراسات والأبحاث ولعدة أسباب منها عدم حث و إرشاد ودعم الفلاح لزر اعته، فضلاً عن عدم وجود أصناف معتمدة من قبل وزارة الزر اعة العر اقية ذات إنتاجية عالية وملائمة للظروف البيئية المحلية.

تحظى در اسة الاستقرارية اهتماما واسعا من قبل مربي النبات عند تخطيطهم لبرامج التربية لأصناف جديدة لاسيما في محصول الشوفان و غيره من المحاصيل الأخرى عند تطبيقها في مدى واسع من البيئات (مثل نوع التربة، موعد الزراعة، أنواع المياه .... الخ) و هي تؤثر منفردة أو مجتمعة في سلوك التر اكيب الور اثية عندما بحدث التداخل بينها وبين بيئة الزراعة، وتناول العديد من الباحثين في دراستهم التراكيب الور اثية ونوع المياه و المواسم في محصول الثوفان منهم [4] و [5] و [6] . وعندما يختلف السلوك النسبي للنزر اكيب الوراثية في البيئات المنباينة شريطة أن هذه التراكيب تجمع بين الحاصل المنفوق والاستقرارية العالية تحت مدى واسع من تغاير البيئات والأخير تفيد في تحديد وانتخاب التركيب التي تتناسب مع الزراعة العامة وأخرى تناسب مناطق خاصة، بعد ما يتجه التركيب لامتلاكه حاصلاً متفوقا في وحدة المساحة عند ظروف بيئية مختلفة وينم اختبار ها من خلال التداخل الور اثي والبيئي وخصوصا طريقة [7] الذي تساعدنا في التعرف على استقرارية آدائها تحت البيئات المختلفة، ومن المعلوم أن هناك عدة طر ائق لقياس الاستقر ارية ولكل طريقة محاسن ومساوىء ولكن بالوقت نفسه جميعها تلبي طموح المربي للوصول إلى الهذف المنشود، وفي هذا المضمار درس كل من [8] و9] و [10] و [11] و [12]

$$
\text { و [13] و[14] و [15] و [16] و[17] الاستقرارية الور اثية في المحاصبل الحبوبية. }
$$

يساهم التحليل العنقودي في تصنيف المتغيرات بصورة عامة ومكن الصفات الظاهرية حسب عوامل الدراسة (المواسم ونوعية مياه الري) للوصول إلى نمط معين يتضمنها وتقسيمها إلى مجموعات تتمتع عناصر ها بخواص مشتركة، وكذلك 
تساعدنا في التنبؤ بمدى سلوك التر اكيب الور اثية على الرغم من اختلاف عو امل الدراسة أي مدى ثباتيتها من عدمها، وقد درس هذا التحليل من قبل العديد من الباحثين في در اساتهم و هم [18] و [19] و [20].

\section{الهُف من البحث}

بناء على ما تقدم جاءت فكرة هذا البحث إلى معرفة أفضل التراكيب الوراثية العشرة ذات المؤشرات المهمة كالحاصل العالي وبعض مكوناته تحت تأثثير ثلاثة أنو اع من مياه الري (بئر ونهر وحوض تربية الأسماك) ولموسمين زر اعيين وتتخيص استقر اريتها باعتماد طريقتين إحصائينن للوصول إلى الهدف المنشود.

\section{2 ـمواد وطر ائق البحث}

نفذت التجربة الحقلية للموسمين 2016-2017 و2017- 2018 في حقول كلية الزر اعة جامعة تكريت الو اقعة شمال مدينة تكريت بين خط عرض 34.67o و خط طول 43.65o بهدف دراسة عاملين: الأول ثلاثة أنواع من مياه الري (بئر ونهر وماء حوض تربية الأسماك) ووضعت في القطع الرئيسية (أخذت نماذج من عينات المياه وحللت لمعرفة بعض خواصها الكيميائية و الفيزيائية في مختبر ات قسم التربة كلية الزراعة جامعة تكريت وحسب جدول (1)، و العامل الثاني عشرة تر اكيب ور اثية من

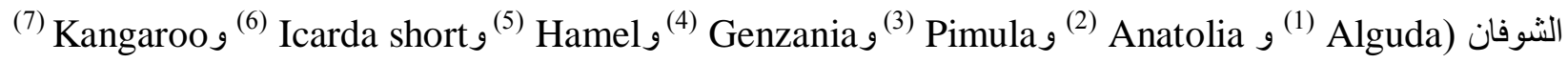
و Mossum و ${ }^{(9)}$ Mitika ${ }^{(8)}$ Icarda tall $\left.\left.{ }^{(10)}\right)^{(10}\right)^{2}$ الحصول عليها من برنامج الزر اعة الحافظة المشترك بين وزارة الزر اعة وجامعة الموصل والمركز الدولي للبحوث الزراعية في المناطق الجافة (ICARDA)، إذ وضعت في القطع الثانوية باستخدام تصميم القطاعات العشو ائية الكاملة R.C.B.D بنظام القطع المنشقة split plot design ، وزعت مسنويات كل عامل على الوحدات التجريبية بصورة عشو ائية بثلاثة مكررات، بحيث احتوى كل مكرر على 30 وحدة تجريبية، واحتوت كل وحدة تجريبية على خطين من كل نركيب بطول 3م للخط الواحد وبمسافة 0.30 م بين خط وأخر وبكمية بذار 100 كغ. هــ1 إذ زرعت البذور في خطوط سرباً، فصل كل مكرر عن الآخر وبين كل وحدة تجريبية ثانوية وأخرى بمسافة 2 و 1 م على التو الي. حرثت أرض التجربة للموسمين بالمحر اث القرصي بحر اثثين متعامدتين ثم نعمت التربة بالخرماشة تمت الزر اعة في 11/25 لكلا الموسمين (2016-2017 و2017-2018). 
جدول (1): الصفات الفيزيائية والكيمياوية لأنو اع مباه الري للموسمين

\begin{tabular}{|c|c|c|c|c|c|c|c|}
\hline \multicolumn{3}{|c|}{ الموسم الثاني 2017-2018 } & \multicolumn{3}{|c|}{ الموسم الأول 2016-2017 } & \multirow{2}{*}{ وحدة القياس } & \multirow{2}{*}{ الصفة } \\
\hline ماء الحوض & ماء النهر & ماء البئر & ماء الحوض & ماء النهر & ماء البئر & & \\
\hline 1.6 & 2.1 & 1.94 & 1.4 & 1.9 & 1.6 & dc.m-1 & $\mathrm{EC}$ \\
\hline 7.7 & 7.05 & 6.20 & 6.87 & 7.14 & 6.17 & - & $\mathrm{PH}$ \\
\hline 0.43 & 0.38 & 0.89 & 0.53 & 0.21 & 0.48 & ملغم.لتر -1 & $\mathrm{P}$ \\
\hline 4.3 & 5.1 & 4.4 & 3.8 & 5.9 & 4.2 & ملغم.لتر -1 & $\mathrm{K}+$ \\
\hline 1.43 & 1.12 & 1.22 & 1.38 & 1.14 & 1.20 & ملغم.لتر -1 & $\mathrm{NO}_{3}$ \\
\hline 135 & 129 & 142 & 144 & 133 & 140 & ملغم.لتر -1 & $\mathrm{Na}+$ \\
\hline 234 & 228 & 243 & 220 & 245 & 221 & ملغم.لتر -1 & $\mathrm{Ca}+2$ \\
\hline 279.4 & 73.12 & 267.3 & 286 & 66 & 270 & ملغم.لتر -1 & $\mathrm{Mg}+2$ \\
\hline 58.47 & 64.2 & 53.5 & 56 & 64.2 & 52 & ملغم.لتر -1 & $\mathrm{Cl}-$ \\
\hline 581.17 & 568.7 & 482.21 & 579 & 576 & 480 & ملغم.لتر -1 & $\mathrm{SO}_{3}{ }^{-2}$ \\
\hline 135.76 & 140.8 & 145.43 & 132 & 142 & 146 & ملغم.لتر -1 & $\mathrm{HCO}_{3}{ }^{-2}$ \\
\hline
\end{tabular}

أجريت عمليات خدمة المحصول كافة وفق التوصيات على محصول الحنطة إذ أضيف السماد السوبر فوسفات بمعدل

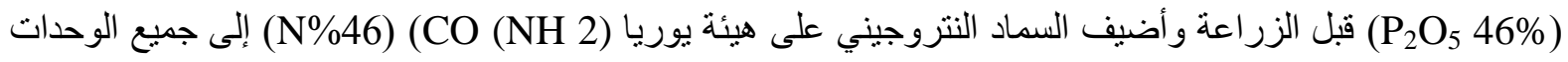
التجرييية بمعدل 100 كغم.هـ-1 على دفعتين الأولى عند الإنبات والثانية في مرحلة البطان [21]. وتم الحصاد يدوياً لكل موسم بعد وصول كل تركيب للنضج التام. ودرست صفات المدة من الزراعة حنى 50\% نزهير يوم-1 وارتفاع النبات(سم.نبات-1): قبس من سطح التربة (قاعدة النبات) إلى قاعدة الدالية للساق الرئيس، [22] ومساحة ورقة العلم (سم2.ورقة-1) = ناتج عن معدل عشر نباتات اختيرت بشكل عشو ائي من كل سطر وتساوي، (الطول × أقصى عرض × معامل التصحيح 0.75)، [23] ، و عدد الأشطاء الفعالة شطأمج2 (يمثل عدد الأشطاء الحاملة للداليات تم حسابها من 1م طول ثم حولت الى م2) و عدد الحبوب حبة. الدالية-1 (أخذ معدل عدد الحبوب في 15 دالية بعد الحصاد) ووزن 1000 حبة حبة.غم-1 (تم وزن 1000 حبه بميزان حساس بعد عدها يدوياً) وحاصل الحبوب طن.هُ1 (تم حساب حاصل الحبوب من حصاد 1م طول من أحد السطرين من كل صنف ثم حول إلى طن.هـ-1.).

تم تحليل البيانات وفق التصميم المستخدم ومعرفة التباين التجميعي عبر البيئات المختبرة، وقورنت الفروقات بين متوسطات كل من التراكيب الوراثية والبيئات بطريقة أقل فرقا معنويا L.S.D. [24]، ولغرض تمييز استقرارية التراكيب الور اثية عند الظروف البيئية المعتمدة في الدراسة (وعددها ست بيئات تمثل ثلاثة أنواع من المياه ولموسمين) استخدم نموذج الانحدار الخطي التالي حسب طريقة [6]، ومن ثم تقدير معلمتين للاستقرار والمستندة على: (1) معامل الانحدار وهو السلوك الانحداري لكل صنف في البيئات المختلفة و(2) الانحراف المنوسط (S di d ) عن الانحدار الخطي واختبرت معنوية معاملات الانحدار للأصناف ولكل صفة من خلال اختبار t. إذ أن معامل الانحدار الخطي bi للعلاقة بين كل صفة من صفات التركيب 
الوراثي في كل بيئة وحاصل وسلوك كل صفة لمعدل البيئة هو مقياس للاستجابة الخطية للتغيرات البيئة. إن منوسط تباين الانحر اف عن الانحدار (S2di) يقيس اتساق هذه الاستجابة، أو بمعنى آخر هي مقياس لعدم التجانس. واعتماداً على هاتين المعلمتين ينم تقييم ثبوتية التر اكيب الور اثية، وفي هذه الحالة عندما تكون (1) S2 di صفر وان bi > 1 فإن التركيب الور اثي

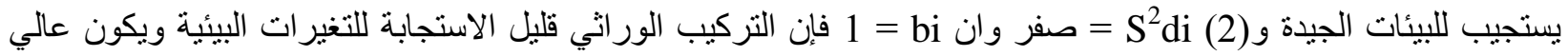

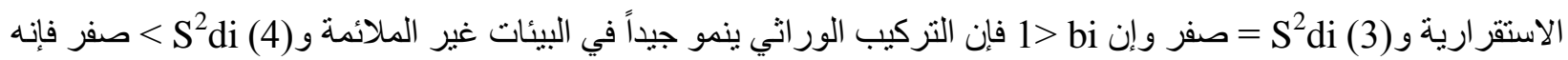
يضعف التنبؤ الخطي [25] ـ تم الاعتماد على الصفات الكمية للتراكيب الوراثية وفق عوامل الدراسة في إجراء التحليل العنقودي لغرض تحديد مجاميع التراكيب الور اثية حسب تقاربها أو تباعدها الور اثي اعتماداً على تشابه استجاباتها للظروف البيئية المدروسة، إذ يعتمد على تحديد مسافات تعبر عن مقدار هذا التباعد وتوزيع التراكيب الور اثية في مجاميع حسب آدائها و أصو لها الور اثية و عو امل الدراسة، وأجريت كافة التحليل بالاستعانة ببرنامج SPSS و Excel. 3

عند الكثف على نتائج جدول (2) لتحليل التباين التجميعي ممثلاً بمتوسط المربعات لحاصل الحبوب وبعض مكوناته المباشرة وغير المباشرة في محصول الثوفان، إذ نلاحظ أن جميع مصادر الاختلاف (التراكيب والبيئات و التداخل بينهما) كانت معنوية عند مستوى احتمال 1\% لجميع الصفات قيد الدراسة، مما يدل على أن هذه التراكيب الوراثية قد سلكت سلوكا مغاير اً من بيئة الى أخرى مما يستدعي ذلك إلى دراسات الاستقرارية لمعرفة أفضل التر اكيب السلوك وثباتاً عبر البيئات المختلفة وتحديد بيئة الهذف لكل تركيب ور اني، وممكن استخدام هذه التر اكيب كمصدر للجينات في برامج التربية المستقبلية، وتنسجم هذه النتائج مع نتائج كل من [8] و [11] و [12] و [16] في هذا الموضوع. جدول (2): تحليل التباين التجميعي ممثلاً بمتوسط المربعات لحاصل الحبوب وبعض مكوناته في الشوفان

\begin{tabular}{|c|c|c|c|c|c|c|c|c|}
\hline طن.هـ-1- حاصل & وزنة (غم) 1000 & الحبوب. عدداد & الاشطاء & ورقة العلم & النبات (سم) & لغاية التز هدير & درجا & الاختلاف \\
\hline 0.70 & 14.08 & 1.072 & 107.77 & 32.49 & 191.29 & 1.71 & 2 & المكرر ات \\
\hline$* * 6.24$ & $* * 41.47$ & $\begin{array}{c}* * 2415 \\
5\end{array}$ & $\begin{array}{c}* * 1032 . \\
3\end{array}$ & $\begin{array}{c}* * 272.1 \\
7\end{array}$ & $\begin{array}{c}* * 822.4 \\
5\end{array}$ & $\begin{array}{c}* * 204.2 \\
5\end{array}$ & 9 & التر اكيب \\
\hline$* * 17.54$ & $* * 81.50$ & $\begin{array}{c}* * 143.6 \\
3 \\
\end{array}$ & $* * 39347$ & $\begin{array}{c}* * 443.0 \\
5 \\
\end{array}$ & $\begin{array}{c}* * 393.0 \\
1 \\
\end{array}$ & $* * 33.26$ & 5 & البيئات \\
\hline$* * 0.73$ & $* * 9.54$ & $* * 53.19$ & $\begin{array}{c}* * 1885 . \\
1\end{array}$ & $* * 55.02$ & $* * 47.03$ & $* * 7.94$ & 45 & G.E التداخل \\
\hline 0.03 & 1.85 & 1.03 & 55.02 & 3.91 & 24.71 & 3.45 & 118 & الخطأ التجريبي \\
\hline
\end{tabular}




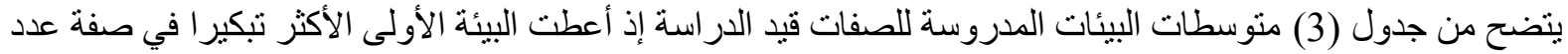

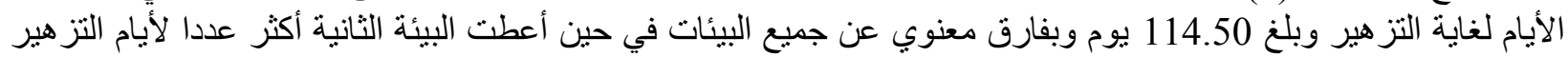

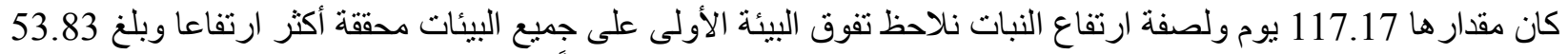

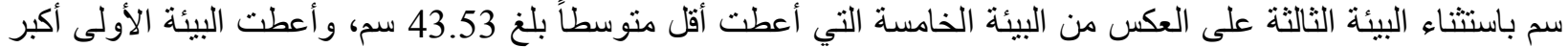

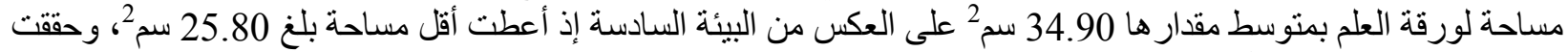

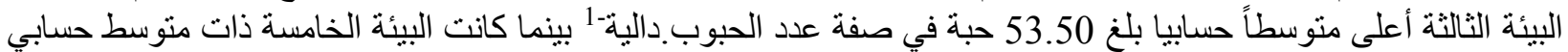

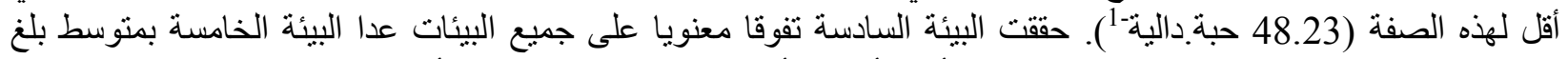

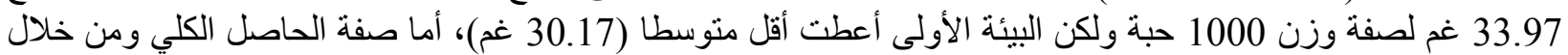

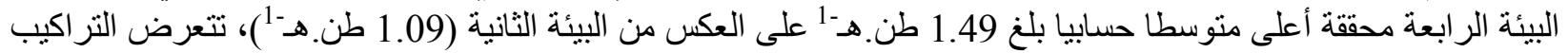

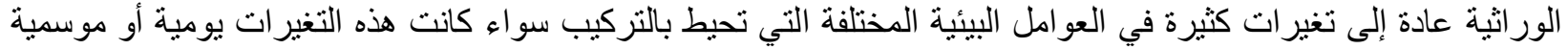

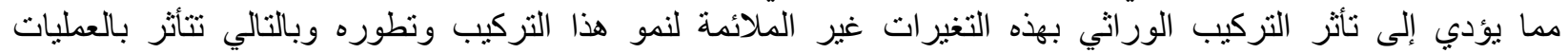

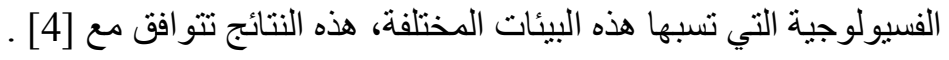
جدول (3): منوسطات البيئات لحاصل الحبوب وبعض مكوناته في الشوفان

\begin{tabular}{|c|c|c|c|c|c|c|c|}
\hline طاصل هـ-1 & حبة (غم) 1000 & عدبد الحبوبدالية & عدد الاشطاء & مساحة ورقة & 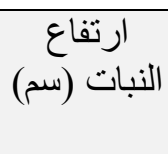 & لغاية التز هير & الصفات \\
\hline 1.37 & 30.17 & 50.03 & 116.33 & 34.90 & 53.83 & 114.50 & الأولى \\
\hline 1.09 & 30.88 & 48.77 & 78.97 & 32.59 & 49.33 & 117.17 & الثانية \\
\hline 1.23 & 30.94 & 53.50 & 94.67 & 26.11 & 52.64 & 114.73 & الثالثة \\
\hline 1.49 & 33.01 & 49.90 & 161.97 & 26.16 & 49.19 & 114.60 & الر ابعة \\
\hline 1.08 & 33.78 & 48.23 & 154.87 & 26.52 & 43.53 & 115.20 & الخامسة \\
\hline 1.23 & 33.97 & 53.00 & 169.93 & 25.80 & 50.94 & 116.10 & السادسة \\
\hline 1.25 & 32.12 & 50.57 & 129.46 & 28.68 & 49.91 & 115.38 & العتوسط \\
\hline 0.09 & 0.70 & 0.52 & 3.79 & 1.01 & 2.54 & 0.95 & L.S.D \\
\hline
\end{tabular}

يظهر من خلال جدول (4) المتوسطات الحسابية للتراكيب الور اثية لكافة الصفات المدروسة ونلاحظ أن التركيب 8 كان من أبكر الأصناف لصفة عدد الأيام لغاية التزهير محققا منوسط قدره 109.67 يوم وباختلاف معنوي عن جميع التراكيب المدروسة باستثناء التركيب (1) في حين كان التركيب (2) ذو المتوسط الأعلى وبلغ 118.17 يوم، دائما نبحث على تراكيب وراثية مبكرة بالتزهير مع إطالة مدة امتلاء الحبة وموعد النضج، وبالوقت نفسه أصبح التركيب (2) ذو المتوسط الأعلى في ارتفاع النبات وبلغ 59.96 سم وبفارق معنوي عن جميع التراكيب ولكن التركيب (10) ذو المتوسط الأقل في هذه الصفة (37.33 سم)، إن التركيب (2) الذي كان منأخرا في فترة التز هير انعكس ذلك على إعطاء أكبر فترة ممكنة لإتاحة أكثر ارتفاع للنبات، أو قد يعود سبب ذلك إلى اختلافها الور اثي من حيث فعالية الجينات مما يجعلها متباينة في الارتفاع أو اختلاف تر اكيب الشوفان قيد الدر اسة في محتو اها الهرموني الذي أدى إلى تباين في ارتفاعها من حيث استطالة السلاميات بتنافسها على الضوء. تفوق التركيب (3) معنويا على جميع التراكيب الوراثية في مساحة ورقة العلم بمتوسط مقداره 34.28 سم² ومن جانب آخر كان التركيب (8) ذو المتوسط الأدنى لهذه الصفة (23.81 سم²)، تمكن التركيب (6) من تحقيق أعلى متوسط وبلغ 141.06 
شطأم-2 وباختلاف معنوي عن جميع التراكيب الور اثية سوى التركيب (1) في حين كان التركيب (10) ذو أقل متوسطا وبلغ 136.67 شطأمج2 في صفة عدد الاشطاء الفعالة، يُعد عدد الحبوب في الدالية واحداً من مكونات الحاصل المهمة في محاصيل الحبوب ويعد هدفاً يحظى باهتمام مربي النبات دائماً وهو من الصفات الكمية التي ترتبط ارتباطا موجباً بالعو امل الور اثية حيث سجل التركيب 6 (66.89 حبة.دالية-1) تفوق معنويا على جميع التراكيب إلا التركيب (4) سجل أقل منوسطا بلغ 38.72 حبة.دالية-1 للتركيب (8) ـ بالنسبة لوزن 1000 حبة برز التركيب (6) ذات المتوسط الأعلى (35.03 غم) تفوق معنوي على الجميع ولكن التركيب (3) أعطى أقل متوسط مقداره 29.30 غم. أما حاصل وحدة المساحة التي تعد المحصلة النهائية لعدة صفات في النبات التي تؤثر بمكونات الحاصل ومنها الزمن اللازم للطورين الخضري و التكاثري ومدة امتلاء الحبة ومعدل نمو ها و عدد الأوراق في النبات ومساحتها و غير ها، و هي تمثل مكونات الحاصل الثانوية في حين أن الرئيسة هي عدد الداليات و عدد حبوبها ووزن ألف حبة أو وزن الحبة، إذ تقدم التركيب (6) على جميع التر اكيب الداخلة في هذه الدراسة بمنوسط حسابي قدره 1.48 طن. هـ-1 بينما كان التركيب (9) ذو المتوسط الأقل في هذه الصفة بلغ 1.04 طن.هـ-1، إن تفوق هذه الصفة ممكن أن يرجع نفس التركيب الذي تفوق في صفتي عدد الأشطاء الفعالة و عدد الحبوب.دالية-1، وهذه النتائج تتطابق نوعا ما مع نتائج

جدول (4): متوسطات التر اكيب الور اثية لحاصل الحبوب وبعض مكوناته في الثوفان

\begin{tabular}{|c|c|c|c|c|c|c|c|}
\hline طاصل هـ-1 & وزنة (غم) 1000 & الحبوب.دالية- & الفعالة الاشطاء & مساحة ورقة & $\begin{array}{c}\text { ارتفاع النبات } \\
\text { (سم) }\end{array}$ & لغاية التز هير & /التر/الصيب الصفات \\
\hline 1.27 & 32.78 & 45.11 & 136.67 & 27.65 & 53.01 & 110.72 & 1 \\
\hline 1.33 & 33.54 & 55.22 & 130.67 & 31.85 & 59.96 & 118.17 & 2 \\
\hline 1.34 & 29.30 & 64.72 & 124.78 & 34.28 & 54.42 & 116.72 & 3 \\
\hline 1.32 & 30.35 & 66.33 & 130.50 & 28.78 & 51.52 & 115.89 & 4 \\
\hline 1.20 & 31.69 & 39.44 & 137.56 & 31.19 & 52.64 & 118.06 & 5 \\
\hline 1.48 & 35.03 & 66.89 & 141.06 & 25.42 & 49.05 & 111.61 & 6 \\
\hline 1.25 & 33.29 & 45.56 & 124.44 & 29.10 & 49.50 & 116.89 & 7 \\
\hline 1.17 & 32.38 & 38.72 & 128.33 & 23.81 & 52.07 & 109.67 & 8 \\
\hline 1.04 & 31.28 & 42.22 & 120.83 & 24.39 & 39.60 & 118.00 & 9 \\
\hline 1.11 & 31.60 & 41.50 & 119.72 & 30.32 & 37.33 & 118.11 & 10 \\
\hline 1.25 & 32.12 & 50.57 & 129.46 & 28.68 & 49.91 & 115.38 & 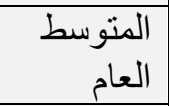 \\
\hline 0.11 & 0.90 & 0.67 & 4.90 & 1.31 & 3.28 & 1.23 & L.S.D \\
\hline
\end{tabular}

الأخرى لا يمكن التنبؤ بها مثل موقع الزراعة وموسم الزر اعة ويعطي كل منها تفاعلا خاصا مع التركيب الور اثي، نرى من جدول (5) المتوسطات الحسابية للتداخل بين البيئات و التر اكيب الوراثية لحاصل الحبوب ومكوناته المباشرة وغير المباثرة في 
محصول الشوفان، وإن أفضل تداخل كان بين (البيئة الرابعة والتركيب 4) لصفة عدد الأيام لغاية التز هير بمنوسط حسابي قدره 107.00 يوم في حين كان التداخل (البيئة الثانية والتركيب4) متأخرا في التزهير وبلغ 121.00 يوم، وهذا الاختلاف سببه سلوك كل تركيب وراثي حسب مادته الور اثية وتأثر ها بظروف بيئة ذلك الموسم مع نوع مياه الري، ولصفة ارتفاع النبات ندرك تفوق التداخل (البيئة الأولى و التركيب2) محققا أعلى متوسط بلغ 67.89 سم وبفارق معنوي على جميع التداخلات بينما كان التداخل (البيئة الثانية والتركيب 10) أقل ارتفاعا وبلغ 33.91 سم، تمكن التداخل (البيئة الأولى والتركيب 2) تفوقا في صفة مساحة ورقة العلم محرزا أعلى متوسط مقداره 49.68 سم² هذا من جهة ومن جهة أخرى كان التداخل (البيئة السادسة مع التركيب 2) ذو المنوسط الأقل في هذه الصفة (18.80 سم²)، و هذا سبب الزيادة من التجميع الحر اري و التمثيل الكاربوني كلما زاد ارتفاع النبات ومساحة ورقته أدت إلى تحويل مواده الأيضية إلى الحبوب الناتجة من التخصيب، وفي صفة عدد الأشطاء الفعالة كان المتوسط 194.00 شطأم-2 من نصيب التداخل (البيئة الر ابعة مع التركيب 7) بينما تر اجع التداخل (البيئة الثانية مع التركيب 7) بمتوسط حسابي قدره 42.00 شطأ.م-2، ويتأثر نشاط بر اعم الأشطاء لكل تركيب بمساحة الورقة و حجم المجموع الجذري و العو امل البيئية لتلك المرحلة. امتلك التداخل (البيئة الثانية مع التركيب5) أعلى متوسط حسابي بلغ 74.00 حبة.دالية 1 وباختلاف معنوي عن جميع التداخلات المطروقة ضمن هذه الدراسة ولكن التداخل (البيئة الخامسة مع التركيب 9) ذو المتوسط الأقل (35.00 حبة.دالية-1) لصفة عدد الحبوب.دالية-1 ، بالنسبة لصفة وزن 1000 حبة كان التفوق واضحا من خلال التداخل (البيئة السادسة مع التركيب 7) بمنوسط حسابي بلغ 37.03 غم في حين تخلف التداخل (البيئة الأولى مع التركيب 3) وبلغ 28.87 غم، وممكن أن يعود السبب إلى انخفاض عدد الحبوب.الدالية-1 مما أدى إلى تراكم نواتج التمثيل الضوئي في الحبوب حسب مبدأ التعويض. أما حاصل وحدة المساحة كان التفوق المعنوي واضحا من خلال التداخل (البيئة الرابعة مع التركيب 6) مسجلا منوسطا 2.32 طن.ه-1 بينما أخفق التداخل (البيئة الثانية مع التركيب 9) بمنوسط بلغ 0.76 طن.ه'، تنسجم هذه النتائج مع نتائج كل من [4] و [5] و [6]. 
جدول (5): المتوسطات الحسابية للتداخل (البيئات و التر اكيب) لحاصل الحبوب وبعض مكوناته في الثوفان

\begin{tabular}{|c|c|c|c|c|c|c|c|}
\hline طن. هـ-1- حاصل & حبة (غم) 1000 & الحبوب.دالية & عدد الاشطاء & 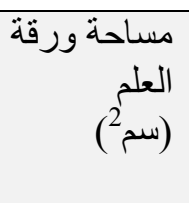 & $\begin{array}{c}\text { ارتفاع النبات } \\
\text { (سم) }\end{array}$ & 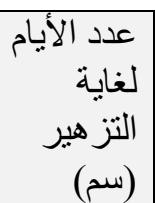 & التداحلغات الصفات \\
\hline 1.44 & 34.53 & 40.33 & 120.33 & 30.90 & 60.91 & 111.33 & البيئة الأولى (1) \\
\hline 1.63 & 31.53 & 59.00 & 131.33 & 49.68 & 67.89 & 117.67 & البيئة الأولى (2) \\
\hline 1.50 & 24.87 & 67.00 & 144.33 & 40.90 & 56.95 & 116.33 & البيئة الأولى (3) \\
\hline 1.14 & 26.00 & 66.67 & 140.33 & 34.01 & 57.56 & 115.00 & البيئة الأولى (4) \\
\hline 1.48 & 28.30 & 59.00 & 99.67 & 35.31 & 58.86 & 117.00 & البيئة الأولى (5) \\
\hline 1.54 & 34.27 & 40.00 & 110.00 & 28.25 & 53.95 & 111.00 & البيئة الأولى (6) \\
\hline 1.12 & 30.27 & 43.00 & 87.33 & 34.35 & 54.90 & 115.00 & البيئة الأولى (7) \\
\hline 1.05 & 30.10 & 41.33 & 95.00 & 30.79 & 52.54 & 109.33 & البيئة الأولى (8) \\
\hline 1.49 & 30.73 & 47.00 & 107.33 & 29.12 & 40.02 & 116.00 & البيئة الأولى (9) \\
\hline 1.27 & 31.07 & 37.00 & 127.67 & 35.70 & 34.74 & 116.33 & البيئة الأولى \\
\hline 1.69 & 33.23 & 42.67 & 104.00 & 33.63 & 56.22 & 111.00 & البيئة الثانية (1) \\
\hline 1.42 & 33.30 & 46.67 & 96.67 & 40.99 & 65.80 & 118.33 & البيئة الثانية (2) \\
\hline 1.00 & 25.77 & 63.67 & 93.33 & 34.53 & 59.55 & 115.67 & البيئة الثانية (3) \\
\hline 1.09 & 26.87 & 66.00 & 76.33 & 34.58 & 50.31 & 118.00 & البيئة الثانية (4) \\
\hline 1.20 & 29.87 & 74.00 & 110.00 & 33.79 & 54.26 & 118.00 & البيئة الثانية (5) \\
\hline 0.84 & 33.73 & 40.33 & 59.33 & 28.87 & 45.97 & 116.67 & البيئة الثانية (6) \\
\hline 1.11 & 32.27 & 42.33 & 42.00 & 31.98 & 38.83 & 121.00 & البيئة الثانية (7) \\
\hline 0.91 & 32.27 & 36.67 & 71.67 & 26.87 & 52.24 & 112.67 & البيئة الثانية (8) \\
\hline 0.76 & 30.33 & 35.67 & 64.00 & 30.10 & 36.22 & 120.33 & البيئة الثانية (9) \\
\hline 0.90 & 31.20 & 39.67 & 72.33 & 30.55 & 33.91 & 120.00 & $\begin{array}{r}\text { البيئة الثانية } \\
\text { (10) }\end{array}$ \\
\hline 1.63 & 29.63 & 53.00 & 96.33 & 25.31 & 54.61 & 111.00 & البيئة الثالثة (1) \\
\hline 1.10 & 35.20 & 61.00 & 81.00 & 35.91 & 62.87 & 117.00 & البيئة الثالثة (2) \\
\hline 1.27 & 25.60 & 64.00 & 63.67 & 34.45 & 56.96 & 117.33 & البيئة الثالثة (3) \\
\hline 1.32 & 27.53 & 67.33 & 117.00 & 26.37 & 55.33 & 115.33 & البيئة الثالثة (4) \\
\hline 0.86 & 29.27 & 68.33 & 112.33 & 25.57 & 54.64 & 117.33 & البيئة الثالثة (5) \\
\hline 1.35 & 34.53 & 38.67 & 102.00 & 25.12 & 56.38 & 111.00 & البيئة الثالثة (6) \\
\hline 1.22 & 32.40 & 52.00 & 67.67 & 23.01 & 52.35 & 117.33 & البيئة الثالثة (7) \\
\hline 1.20 & 30.93 & 38.67 & 107.33 & 19.54 & 55.72 & 111.00 & البيئة الثالثة (8) \\
\hline 1.12 & 32.17 & 45.00 & 100.67 & 20.67 & 41.25 & 114.67 & البيئة الثالثة (9) \\
\hline 1.26 & 32.13 & 47.00 & 98.67 & 25.11 & 36.31 & 115.33 & البيئة الثالثة \\
\hline 0.86 & 31.27 & 39.67 & 175.33 & 25.36 & 48.45 & 110.00 & البيئة الر ابعة \\
\hline 1.41 & 32.12 & 58.00 & 129.00 & 21.50 & 54.44 & 119.00 & البيئة الر ابعة \\
\hline 1.15 & 32.56 & 40.00 & 191.33 & 31.94 & 51.43 & 116.00 & البيئة الر ابعة \\
\hline 1.90 & 34.98 & 66.00 & 143.00 & 25.91 & 54.34 & 114.00 & البيئة الر ابعة \\
\hline 1.96 & 33.37 & 59.00 & 170.00 & 30.84 & 54.52 & 116.00 & البيئة الر ابعة \\
\hline
\end{tabular}




\begin{tabular}{|c|c|c|c|c|c|c|c|}
\hline & & & & & & & (5) \\
\hline 2.32 & 36.06 & 66.67 & 160.67 & 23.43 & 47.32 & 110.00 & البيئة الرابعة \\
\hline 1.54 & 33.61 & 42.67 & 194.00 & 28.42 & 53.40 & 117.00 & البيئة الرابعة \\
\hline 1.63 & 33.64 & 41.00 & 190.00 & 21.89 & 51.35 & 107.00 & البيئة الر ابعة \\
\hline 1.00 & 31.99 & 46.33 & 142.33 & 22.15 & 37.32 & 119.00 & (9) البيئة الر ابعة \\
\hline 1.13 & 30.54 & 39.67 & 124.00 & 30.19 & 39.32 & 118.00 & البرابعة (10) \\
\hline 0.94 & 33.94 & 42.33 & 151.33 & 24.09 & 40.51 & 111.00 & البيئة الخامسة \\
\hline 1.13 & 33.29 & 46.33 & 186.00 & 24.20 & 51.32 & 116.00 & البيئة الخامسة \\
\hline 0.96 & 33.93 & 63.33 & 145.33 & 36.82 & 46.29 & 116.00 & (3) البيئة الخامسة \\
\hline 1.04 & 33.93 & 65.33 & 163.00 & 25.10 & 43.25 & 116.00 & البيئة الخامسة \\
\hline 1.54 & 33.76 & 73.33 & 163.33 & 26.52 & 42.26 & 119.00 & (5) البيئة الخامسة \\
\hline 1.10 & 35.70 & 39.67 & 173.33 & 22.82 & 41.44 & 112.00 & البيئة الخامسة \\
\hline 0.99 & 34.14 & 41.67 & 177.33 & 28.02 & 47.21 & 116.00 & البيئة الخامسة \\
\hline 1.11 & 35.10 & 36.33 & 131.33 & 22.73 & 48.29 & 109.00 & البيئة الخامسة \\
\hline 0.90 & 31.84 & 35.00 & 132.33 & 23.21 & 39.38 & 118.00 & (9) البيئة الخامسة \\
\hline 1.08 & 32.15 & 39.00 & 125.33 & 31.74 & 35.31 & 119.00 & الخامسة (10) \\
\hline 1.05 & 34.09 & 52.67 & 172.67 & 26.62 & 57.37 & 110.00 & البيئة السادسة \\
\hline 1.30 & 35.81 & 60.33 & 160.00 & 18.80 & 57.45 & 121.00 & البيئة السادسة \\
\hline 1.01 & 33.07 & 63.67 & 141.33 & 27.07 & 55.37 & 119.00 & البيئة السادسة \\
\hline 1.41 & 32.81 & 66.67 & 143.33 & 26.73 & 48.30 & 117.00 & (4) البيئة السادسة \\
\hline 1.82 & 35.60 & 67.67 & 191.00 & 35.16 & 51.28 & 121.00 & البيئة السادسة \\
\hline 1.19 & 35.87 & 38.00 & 189.33 & 24.04 & 49.27 & 109.00 & البيئة السادسة \\
\hline 1.49 & 37.03 & 51.67 & 178.33 & 28.82 & 50.30 & 115.00 & البيئة السادسة \\
\hline 1.10 & 32.23 & 38.33 & 174.67 & 21.05 & 52.27 & 109.00 & البيئة السادسة \\
\hline 0.93 & 30.63 & 44.33 & 178.33 & 21.09 & 43.42 & 120.00 & البيئة السادسة \\
\hline
\end{tabular}




\begin{tabular}{|c|c|c|c|c|c|c|c|}
\hline & & & & & & & (7) \\
\hline 1.00 & 32.51 & 46.67 & 170.33 & 28.64 & 44.35 & 120.00 & البيئة السادسة \\
\hline 0.86 & 31.27 & 39.67 & 175.33 & 25.36 & 48.45 & 110.00 & البيئة السادسة \\
\hline 1.41 & 32.12 & 58.00 & 129.00 & 21.50 & 54.44 & 119.00 & البيئة السادسة \\
\hline 1.25 & 32.12 & 50.57 & 129.46 & 28.68 & 49.91 & 115.38 & المتوسط العام \\
\hline 0.28 & 2.20 & 1.64 & 11.99 & 3.20 & 8.04 & 3.00 & L.S.D \\
\hline
\end{tabular}

كثير ا ما يقوم مربو النبات وحدهم في وضع أهدافهم من أجل إنشاء ظروف معينة لبحوثهم معززا ذلك من تأثير الأدوات العلمية في تسخير إمكانات المواد الور اثية النباتية، ويجب أن تتكيف الأصناف الجديدة مع العوامل الددروسة أمر لا غنى عنه لتحقيق النجاح، عند ملاحظة نتائج جدول (6) تحليل التباين التجميعي للاستقرارية بطريقة [7] للصفات كافة، وفيه نلاحظ أن متوسط مربعات البيئات الخطي كان معنوياً عند مستوى احتمال (1\%) لجميع الصفات قيد الدراسة ملوحاً بذلك على قوة هذه الصفات تحت السيطرة الور اثية، وكذلك كان مصدر الاختلاف العائد للمكون الخطي لتداخل التراكيب الور اثية X البيئات عند اختباره ضد الخطأ المتجمع كان معنوياً عذد مستوى احتمال 1\% لجميع الصفات المدروسة باستثاء صفة عدد الأيام لغاية التز هير كان معنويا عند مستوى احتمال 5\%، وان متوسط مربعات الانحراف المتجمع لهما غير معنوي لصفات عدد الأيام لغاية التزهير وارتفاع النبات ووزن 1000 حبة، ويرجع ذلك على أن المكون الرئيسي للاختلافات في ثبوتية التر اكيب الور اثية لهذه الصفات يعود إلى الانحدار الخطي، وأن إمكانية التنبؤ بها ممكنة، في حين صفات مساحة ورقة العلم و عدد الأشطاء الفعالة و عدد الحبوب في الدالية والحاصل الكلي كان لكلا الدكونين معنويا وهذا يعني أن الاختلافات في ثبوتية التراكيب الوراثية معززا ذلك إلى كل من الانحدار الخطي والانحر اف عن الدالة الخطية، وتتو افق هذه النتائج مع نتائج كل من [8] و [9] و

\begin{tabular}{|c|c|c|c|c|c|c|c|c|}
\hline طن.-هـ-1 & وزن 1000 حبة & دالية-1حبوب. & الفعالة & ورمة العلم & النبات (سم) & لغاية الأيام & ات & S .O.V \\
\hline$* * 6.24$ & $* * 41.47$ & $\begin{array}{c}* * 2415 . \\
5\end{array}$ & $\begin{array}{c}* * 1032 . \\
3\end{array}$ & $\begin{array}{c}* * 272.1 \\
7\end{array}$ & $\begin{array}{c}* * 822.4 \\
5\end{array}$ & $\begin{array}{c}* * 204.2 \\
5\end{array}$ & 9 & Geno \\
\hline$* * 17.54$ & $* * 81.50$ & $\begin{array}{c}* * 143.6 \\
3 \\
\end{array}$ & **39347 & $\begin{array}{c}* * 443.0 \\
5\end{array}$ & $\begin{array}{c}* * 393.0 \\
1 \\
\end{array}$ & $* * 33.26$ & 5 & Einvr \\
\hline$* * 0.73$ & $* * 9.54$ & $* * 53.19$ & $\begin{array}{c}* * 1885 . \\
1\end{array}$ & $* * 55.02$ & $* * 47.03$ & $* * 7.94$ & 45 & $G^{*} \mathrm{E}$ \\
\hline
\end{tabular}




\begin{tabular}{|c|c|c|c|c|c|c|c|c|}
\hline$* * 0.62$ & $* * 4.43$ & 11.11 & $\begin{array}{c}* * 1495 \\
4\end{array}$ & 19.74 & 16.92 & 1.48 & 50 & E+G*E \\
\hline$* * 11.70$ & $* * 54.34$ & $* * 95.76$ & $\begin{array}{c}* 26231 \\
.\end{array}$ & $\begin{array}{c}* * 295.3 \\
7\end{array}$ & $\begin{array}{c}* * 262.0 \\
1\end{array}$ & $* * 22.18$ & 1 & $\mathrm{E} \mathrm{Li}$ \\
\hline$* * 2.17$ & $* * 18.56$ & $* * 51.07$ & $\begin{array}{c}* * 5393 \\
1\end{array}$ & $* * 76.87$ & $* * 64.89$ & $* 5.76$ & 9 & $\mathrm{G} * \mathrm{E} \mathrm{Li}$ \\
\hline 0.23 & 1.44 & 12.05 & 477.14 & 14.41 & 12.86 & 2.51 & 40 & Pool Div \\
\hline 0.05 & 2.06 & 1.04 & 55.91 & 4.39 & 27.49 & 3.42 & 120 & Pool Error \\
\hline
\end{tabular}

ثمة حاجة ملحة لاستحداث وطأة أصناف مناسبة ولكي يتم إنجاز ذلك ينبغي جهود منظافرة لاعم هذا الموضوع وبالذات في مجال تربية النبات لاسيما برامج تحسين المحاصيل الموجهة نحو تحقيق النتائج المرجوة من أجل تحقيق الهدف المنشود. عند عرض المعلمات الاستقرارية لحاصل الحبوب ومكوناته في محصول الثوفان حسب ما مثبت في جدول (7)، إذ أعطى التركيب الور اثي (1) في صفة عدد الأيام لغاية التزهير ذو قيمة معامل الانحدار معنوي و أقل من واحد وقيمة الانحراف عن الانحدار غير معنوي وذات منوسط مرغوب، مما يشير إلى استجابتها العالية وتكيفه مع البيئات المواتية التي توفر فيها المنطلبات الحيوية للنمو والتطور وبالمقابل إلى حساسيتها للتغير ات البيئية، والتركيب (4) والذي يتميز باستقر ارية عالية لهذه الصفة أما بقية التراكيب فكانت معنوية للمعلم S d أي يضعف التنبأ بها في استقراريتها. حقق التركيبان الوراثيان (8 و9) معنوية الانحدار وقيمة الانحدار عن الانحراف غير معنوي وبمتوسط أعلى من المتوسط العام مما يثير إلى استجابتهما العالية للبيئات الجيدة، وأن التراكيب (3 و4 و5 و6) ذات استقرارية عالية والتركيب (1) معنوية لمعلمتي الاستقرارية أي أنه غير مستقر وأما التركيبين الور اثيين (2 و10) معنوي للانحر اف عن الانحدار بالتالي يصعب التنبؤ بهما في صفة ارتفاع النبات. أحرز التركيب الوراثي (2) في مساحة ورقة العلم استقراريته للبيئات المختلفة ولكن بقية التراكيب الوراثية كانت معنوية للانحر اف عن الانحدار وبالتالي يضعف التنبأ بهم. ولصفة عدد الأشطاء الفعالة نلاحظ أن التر اكيب (4 و6 و7) كانت معنوية S 2 ما يدل ذلك على أنها غير مستقرة ضمن البيئات المدروسة بينما بقية التراكيب كانت فقط معنوية للمعلم ملوحا بذللى على أن هذه التر اكيب الوراثية يضعف التنبؤ في استقر اريتها ضمن هذه الصفة. ولصفة عدد الحبوب .دالية-1 نرى أن التركيبين (4 و 6) ذات دلالة معنوية و اقل من واحد عكس الانحر اف عن الانحدار كان غير معنوي وبمنوسط حسابي أعلى للتركيب (4) مما يشير الى استجابتها العالية وتكيفها مع البيئات المواتية عكس التركيب (6) الذي امتلك متوسط اقل من المتوسط العام ملوحا بذلك إلى حساسيتها للتغيرات البيئية واستجابتها المختلفة لمدخلات العليات الزراعية أي لا ينصح بزر اعتها إلا في المواقع المتماتلة، وكانت التراكيب الوراثية (1 و3 و7) معنوية لكليهما أي أنهما غبر مستقران، وأما بقية التر اكيب الور اثية كانت معنوية للانحر اف عن الانحدار بالتالي يصعب التنبؤ بها. تميز التركيب (6) لعدم حصوله على معنوية الانحدار و الانحراف عن الانحدار وبذلك يعتبر أن هذا التركيب مستقراً ضمن البيئات المدروسة، والتركيبان (5 و10) ذو 
معنوية للانحدار وبمتوسط أقل من المتوسط العام في وزن 1000 حبة مما يدل على حساسيتها للتغيرات البيئية واستجابتها المنخفضة لتحسين مدخلات العمليات الزراعية، والتراكيب الوراثية (3 و4 و9) غير مستقرة بسبب معنوية كلتا معلمات الاستقر ارية ولكن بقية التر اكيب الور اثية لهذه الصفة كانت معنوية للانحر اف عن الانحدار مما يؤدي إلى ضعف التنبأ بهما. أما صفة حاصل وحدة المساحة نلاحظ أن التركيبين الوراثيين (1 و 6) غير معنوية لمعلمتي الانحدار والانحر اف عن الانحدار وكان التركيب (1) أعلى من المتوسط العام للصفة مما يشير ذلك على تحمله للظروف غير المواتية وثباتها واستقر اريته وقلة تأثره بالظروف البيئية مما يدل على استجابتها لتحسن الظروف البيئية ولكن التركيب (6) كان ذو منوسط أقل من المعدل العام مما يشير إلى عدم تأثرها بالتغيرات البيئية وانخفاض تكيفها مع البيات المجهدة ولذلك ينصح بزراعتها في البيئات المواتية، وكان التركيب (7) ذات معنوية للانحدار و الانحر اف عن الانحدار غير معنوي مما يستجيب للبيئات الجيدة ولكن بقية التر اكيب الور اثية كانت معنوية للانحر اف عن الانحدار مما يصعب التنبؤ في استقراريتها. استتادا لما تقدم نلاحظ أن التراكيب التالية كانت عالية الاستقرارية ومن ضمنها التركيب (6) لصفات ارتفاع النبات ووزن ألف حبة وحاصل وحدة المساحة والتركيب (4) لصفتي عدد الأيام لغاية التز هير و ارتفاع النبات والتركيب (1) للحاصل الكلي و التركيبين (3 و 5) لارتفاع النبات وبالتالي يمكن الاستفادة من هذه التر اكيب الوراثية في برامج التربية المستقبلية للوصول الى صنف ذات إنتاجية عالية إضافة إلى استجابتها لمدى و اسع من البيئات، وتنسجم هذه النتائج مع نتائج كل من [10] و [11] و [14] و [15] و16] و[17]. جدول (7): معلمات الاستقرارية لحاصل الحبوب وبعض مكوناته في الثوفان

\begin{tabular}{|c|c|c|c|c|c|c|c|c|}
\hline \multicolumn{2}{|c|}{ عدد الاشطاء الفعالة } & \multicolumn{2}{|c|}{ مساحة ورقة العلم (سم²) } & \multicolumn{2}{|c|}{ ارتفاع النبات (سم) } & \multicolumn{2}{|c|}{ عدد الأيام لغاية الز هير } & \multirow[t]{2}{*}{ ب التر اكي } \\
\hline $\mathrm{S}^{2} \mathrm{~d}_{\mathrm{i}}$ & $\mathrm{B}_{\mathrm{i}}$ & $\mathrm{S}^{2} \mathrm{~d}_{\mathrm{i}}$ & $\mathrm{B}_{\mathrm{i}}$ & $\mathrm{S}^{2} \mathrm{~d}_{\mathrm{i}}$ & $\mathrm{B}_{\mathrm{i}}$ & $\mathrm{S}^{2} \mathrm{~d}_{\mathrm{i}}$ & $\mathrm{B}_{\mathrm{i}}$ & \\
\hline$* * 254.59$ & 0.93 & $* * 4.04$ & 0.83 & $* 7.35$ & $* 1.85$ & -0.15 & $*_{-} 0.04$ & 1 \\
\hline$* * 888.52$ & 0.83 & $* * 48.08$ & $* 2.65$ & $* * 17.20$ & 1.41 & $* * 2.71$ & 0.59 & 2 \\
\hline$* * 828.93$ & 0.66 & $* * 15.48$ & 0.59 & 6.09 & 1.05 & $* * 1.39$ & 0.07 & 3 \\
\hline$* * 214.20$ & $* 0.61$ & $* * 3.48$ & 0.75 & 4.44 & 1.26 & -0.289 & 1.29 & 4 \\
\hline$* * 392.18$ & 0.67 & $* * 36.32$ & 0.55 & 2.46 & 1.41 & $* * 2.23$ & 0.88 & 5 \\
\hline$* * 254.01$ & $* 1.48$ & $* * 2.85$ & 0.65 & 0.84 & 1.39 & $* * 4.52$ & 1.67 & 6 \\
\hline$* * 364.09$ & $* * 1.81$ & $* * 4.50$ & 0.91 & $* * 29.79$ & 0.73 & $* * 3.20$ & 1.34 & 7 \\
\hline$* * 744.08$ & 1.27 & $* * 2.11$ & 1.08 & -2.54 & $* * 0.56$ & $* * 2.24$ & 1.17 & 8 \\
\hline$* * 484.42$ & 0.96 & $* * 1.87$ & 1.14 & 3.12 & $* 0.23$ & $* * 2.37$ & 1.58 & 9 \\
\hline$* * 253.94$ & 0.79 & $* * 18.11$ & 0.86 & $* * 14.42$ & 0.12 & $* * 1.23$ & 1.45 & 10 \\
\hline
\end{tabular}


تابع الجدول (7)

\begin{tabular}{|c|c|c|c|c|c|c|}
\hline \multicolumn{2}{|c|}{ حاصل طن. هـ-1 } & \multicolumn{2}{|c|}{ وزن 1000 حبة (غم) } & \multicolumn{2}{|c|}{ عدد الحبوب.دالية-1 } & \multirow{2}{*}{ التر اكي } \\
\hline $\mathrm{S}^{2} \mathrm{~d}_{\mathrm{i}}$ & $\mathrm{B}_{\mathrm{i}}$ & $\mathrm{S}^{2} \mathrm{~d}_{\mathrm{i}}$ & $\mathrm{B}_{\mathrm{i}}$ & $\mathrm{S}^{2} \mathrm{~d}_{\mathrm{i}}$ & $\mathrm{B}_{\mathrm{i}}$ & \\
\hline 0.06 & 0.82 & $* * 2.44$ & 0.33 & $* * 10.35$ & $* 2.45$ & 1 \\
\hline$* * 0.21$ & 0.97 & $* * 2.08$ & 0.38 & $* * 18.55$ & 2.58 & 2 \\
\hline$* * 0.44$ & 1.03 & $* 0.64$ & $* * 2.37$ & $* * 3.19$ & $* *-0.09$ & 3 \\
\hline$* * 0.17$ & 1.03 & $* * 2.17$ & $* * 2.19$ & -0.03 & $* * 0.28$ & 4 \\
\hline$* * 0.62$ & 1.11 & 0.37 & $* * 1.70$ & $* * 53.07$ & -0.51 & 5 \\
\hline 0.08 & 1.11 & 0.14 & 0.72 & 0.09 & $* *-0.36$ & 6 \\
\hline 0.02 & $* * 1.63$ & $* * 1.15$ & 1.21 & $* * 1.47$ & $* * 2.17$ & 7 \\
\hline$* * 0.21$ & 0.92 & $* * 1.24$ & 0.86 & $* * 5.06$ & 0.22 & 8 \\
\hline$* * 0.20$ & 0.72 & $* 0.44$ & $* * 0.08$ & $* * 22.56$ & 1.53 & 9 \\
\hline$* * 0.15$ & 0.66 & 0.31 & $* * 0.16$ & $* * 4.41$ & 1.73 & 10 \\
\hline
\end{tabular}

يعتبر التحليل العنقودي من الطر ائق الإحصائية المهمة المستخدمة في التصنيف والتي تعنمد بدور ها على البيانات الظاهرية للصفات المدروسة ويتم تصنيفها اعتماداً على التشابه والاختلاف بين الصفات، وممكن استخدامه في هذا البحث للوصول إلى التركيب الور اثي و الذي ينتقل بين عنقود وآخر على الرغم من اختلاف البيئات المدروسة، وبالتالي يمكن اعتباره ثابتا، يبدو من الثكل (1) شجرة القرابة الور اثية للتر اكيب الور اثية العشرة المدروسة والمختبرة ضمن البيئات الست (موسمين وثلاثة أنواع من مياه السقي بئر ونهر وحوض تربية الأسماك) حيث انقسمت البيانات إلى مجموعنين رئيسنين، إذ تمثل كل مجموعة موسم زر اعي واختلف كل موسم عن الآخر واندرجت التراكيب الور اثية المروية بمياه مختلفة في مجاميع ثانوية، ومن ثم إلى ثانوية أخرى ومن ثم إلى ثانوية أخرى و هكذا ..... الخ، نلاحظ من خلال الثكل أن المجموعة الرئيسية الأولى (الموسم الأول) تمثلت بالتركيب الور اثي 5 و المروي بماء بئر ونهر كان ذو سلوك مشابه وغير مختلف لأغلب الصفات المدروسة بضمنها الحاصل (جدول 5) وكذللك وقوع التركيب (1) المروي بماء بئر والنهر في مجموعة واحدة ضيقة إضافة إلى وقوع نفس التركيب المروي بماء الحوض للموسم نفسه في عنقود مجاور ضمن نفس المجموعة الثانوية الثانوية، مما يدل ذلك على أن هذا التركيب كان سلوكه ثابت على الرغم من اختلاف الماء إضافة إلى سلوكه عبر البيئات مقاربا نوعا ولصفات عدد الأيام للتز هير وعدد الحبوب ووزن 1000 حبة وأخير ا ضمن هذه المجموعة (الرئيسية الأولى) وقوع التركيب الوراثي (7) المروي بماء بئر ونهر في نفس المجموعة متجاورين أي أن آداه كان ثابتا على الرغم من اختلاف ماء السقي وكذلك ذو متوسطات مقاربة نوعا ما لصفات مساحة ورقة العلم وعدد حبوب.دالية-1 ووزن 1000 حبة والحاصل الكلي (جدول 5)، أما المجوعة الرئيسية الثانية (الموسم الثاني) نلاحظ أن التركيبين الور اثيين (6 و7) كان سلوكهما ثابت على الرغم من اختلافهما بمياه السقي الثناثة (بئر ونهر وحوض ) وقوعهم في مجاميع ثانوية متجاورة وذات متوسطات متقاربة نوعا ما ولمعظم الصفات قيد الدراسة وكذللك 
وقوع التركيب الور اثي (10) في مجموعة واحدة و متجاورة المروية بمياه البئر والنهر كان سلوكه مقاربا ولجميع الصفات قبد الدر اسة، وأخير ا التركيبين الور اثثين (2 و 3) في مجموعة واحدة ومتجاورة الروية بماء البئر والحوض بالنسبة للتركيب الأول وماء النهر و الحوض للتركيب الثاني وكان سلوكهما ذو تغاير قليل ولكافة الصفات المدروسة، نستنتج لما سبق أن التراكيب الور انية الآنفة الذكر كانت ذات سلوك منوسط للاستقر ارية لأنها كانت ضمن البيئات الصغيرة ذو استقرارية عالية ولكن ضمن البيئات الواسعة قد يصعب التنبأ بها. عند الرجوع إلى التحليل العنقودي وملاحظة البعد الور اثي بين التر اكيب الوراثية المختبرة ضمن البيئات وبالوقت نفسه تعذر عرض الجدول لكبر حجمهاو عدم استيعابه في هذا البحث، إذ نلاحظ أن أكبر بعد ور اثي كان بين التركيب الوراثي (8) المروي بماء البئر للموسم الثاني مع التركيبين (7 و6) المروي بنفس الماء ضمن الموسم الأول مقدار ها 23154.87 و 2311 على الترتيب وممكن استغلال هذه الإباء في برامج التربية لاسيما التهجين لوجود أكبر بعد وراثي بين التر اكيب الور اثية بينما كان أقل بعد ور اثي بين التركيبين الوراثيين (4 و5) المروية بماء البئر ضمن الموسم الأول وبمسافة قدر ها 17.73، وتتلائم هذه النتائج مع كل من [18] و [19] و [20] .

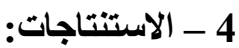

نستتج مما سبق حول هذه الدر اسة نلاحظ أن التركيب الوراثي Icarda short (6) إضافة إلى تداخله مع البيئة الرابعة (الموسم الثاني المروية بماء البئر) تفوقا في صفات عدد الأشطاء و عدد الحبوب والحاصل الكلي إضافة إلى تميزه و لأكثر من صفة في الثباتية والاستقرارية كونها تتلائم مع منطلبات وإمكانيات البيئة المدروسة إضافة إلى البعد الوراثي بينه وبين التركيبين الور اثيين Kangaroo (7) و Icarda tall (8) مما يشجع على اعتماهما في برامج التربية سو اء كان الاعتماد عليها في الادخال لهذا الغرض أو إمكانية التوسع بزر اعتها عند مدى واسع من الظروف البيئة و لاسيما العر اقية. 


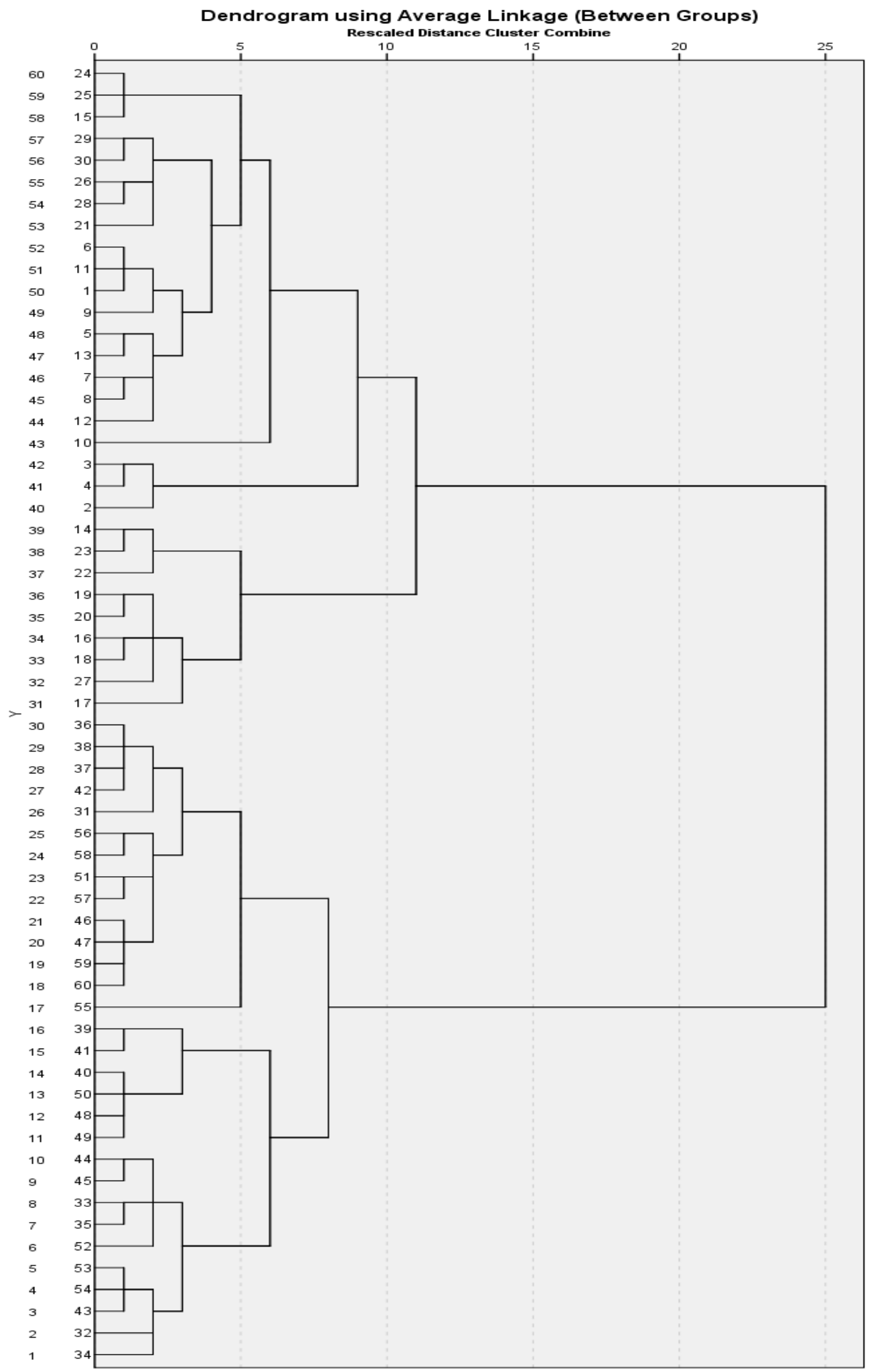

شكل (1): شجرة القر ابة الور اثثية للتر اكيب الور اثية العشرة المروية بمياه مختلفة 
جدول بالمختصر ات للتر اكيب الور اثية المروية بمياه مختلفة ولموسمين زر اعيين

\begin{tabular}{|c|c|c|c|c|c|c|c|}
\hline الموسم & نوع مياه السقي & اسم التركيب & تلتركلب & الموسم & نوع مياه & اسم التركيب & تلتركلب \\
\hline $2018-2017$ & بئر & Alguda & 31 & $2017-2016$ & بئر & Alguda & 1 \\
\hline 2018-2017 & بئر & Anatolia & 32 & $2017-2016$ & بئر & Anatolia & 2 \\
\hline $2018-2017$ & بئر & Pimula & 33 & $2017-2016$ & بئر & Pimula & 3 \\
\hline $2018-2017$ & بئر & Genzania & 34 & $2017-2016$ & بئر & Genzania & 4 \\
\hline $2018-2017$ & بئر & Hamel & 35 & $2017-2016$ & بئر & Hamel & 5 \\
\hline $2018-2017$ & بئر & $\begin{array}{c}\text { short } \\
\text { Kangaroo }\end{array}$ & 36 & $2017-2016$ & بئر & $\begin{array}{c}\text { short } \\
\text { Kangaroo }\end{array}$ & 6 \\
\hline $2018-2017$ & بئر & Icarda & 37 & $2017-2016$ & بئز & Icarda & 7 \\
\hline 2018-2017 & بئر & Icarda tall & 38 & $2017-2016$ & بئز & Icarda tall & 8 \\
\hline $2018-2017$ & بئر & Mitika & 39 & $2017-2016$ & بئر & Mitika & 9 \\
\hline $2018-2017$ & بئر & Possum & 40 & $2017-2016$ & بئر & Possum & 10 \\
\hline $2018-2017$ & نهر & Alguda & 41 & $2017-2016$ & نهر & Alguda & 11 \\
\hline $2018-2017$ & نهر & Anatolia & 42 & $2017-2016$ & نهر & Anatolia & 12 \\
\hline $2018-2017$ & نهر & Pimula & 43 & $2017-2016$ & نهر & Pimula & 13 \\
\hline $2018-2017$ & نهر & Genzania & 44 & $2017-2016$ & نهز & Genzania & 14 \\
\hline $2018-2017$ & نهر & Hamel & 45 & $2017-2016$ & نهر & Hamel & 15 \\
\hline $2018-2017$ & نهر & $\begin{array}{c}\text { short } \\
\text { Kangaroo }\end{array}$ & 46 & $2017-2016$ & نهر & $\begin{array}{c}\text { short } \\
\text { Kangaroo }\end{array}$ & 16 \\
\hline $2018-2017$ & نهر & Icarda & 47 & $2017-2016$ & نهز & Icarda & 17 \\
\hline $2018-2017$ & نهر & Icarda tall & 48 & $2017-2016$ & نهر & Icarda tall & 18 \\
\hline $2018-2017$ & نهر & Mitika & 49 & $2017-2016$ & نهر & Mitika & 19 \\
\hline $2018-2017$ & نهر & Possum & 50 & $2017-2016$ & نهر & Possum & 20 \\
\hline $2018-2017$ & حوض الأسماك & Alguda & 51 & $2017-2016$ & الأسمالك & Alguda & 21 \\
\hline $2018-2017$ & حوض الأسماك & Anatolia & 52 & $2017-2016$ & الأسماك & Anatolia & 22 \\
\hline $2018-2017$ & حوض الأسماك & Pimula & 53 & $2017-2016$ & الأسماك & Pimula & 23 \\
\hline $2018-2017$ & حوض الأسماك & Genzania & 54 & $2017-2016$ & الأسماك & Genzania & 24 \\
\hline $2018-2017$ & حوض الأسماك & Hamel & 55 & $2017-2016$ & الأسماك & Hamel & 25 \\
\hline $2018-2017$ & حوض الأسماك & $\begin{array}{c}\text { short } \\
\text { Kangaroo }\end{array}$ & 56 & $2017-2016$ & الأسماك & $\begin{array}{c}\text { short } \\
\text { Kangaroo }\end{array}$ & 26 \\
\hline $2018-2017$ & حوض الأسماك & Icarda & 57 & $2017-2016$ & الأسماك & Icarda & 27 \\
\hline $2018-2017$ & حوض الأسماك & Icarda tall & 58 & $2017-2016$ & الأسماك حوض & Icarda tall & 28 \\
\hline $2018-2017$ & حوض الأسماك & Mitika & 59 & $2017-2016$ & الأسماك & Mitika & 29 \\
\hline $2018-2017$ & حوض الأسماك & Possum & 60 & $2017-2016$ & الأسماك & Possum & 30 \\
\hline
\end{tabular}




\begin{tabular}{|c|c|c|c|c|c|}
\hline الاسم الكامل & اسم المختصر & $ت$ & الاسم الكامل & اسم المختصر & $ت$ \\
\hline غرام & غم & 2 & مليغر ام & ملغم & 1 \\
\hline سنتيمتر & سم & 4 & كيلو غرام & كغم & 3 \\
\hline اختبار اقل فرق معنوي & LSD & 6 & هكتار & $1-0$ & 5 \\
\hline معامل الانحدار & $b_{i}$ & 8 & الانحر اف المتوسط & $\mathrm{S}^{2} \mathrm{~d}_{\mathrm{i}}$ & 7 \\
\hline & & & الاجنماعية الإحصائية للعلوم & SPSS & 9 \\
\hline
\end{tabular}


[1] W. Biel, K.Bobko, R.Maciorowski, (Chemical composition and nutritive value of husked and naked oats grain) J. of cereal Sci . 49 (3) (2009):413-418.

[2] USDA, ( National Nutrient Database for Standard Reference) Software developed by the National Agricultural Library.3(9) (2018).

[3] N. Gray, (Oatmeal for breakfast may increase satiety and mean a lower calorie lunch)-27 Jan-(2015).

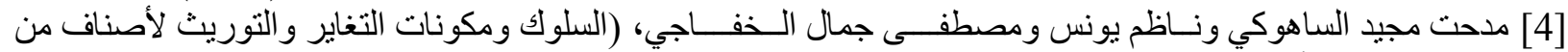

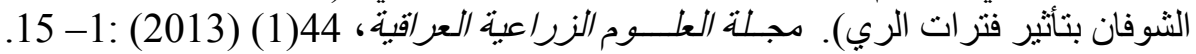

[5] M.Choudhary, G.Prabhu, (Response of fodder Oat (Avena sativa L.) varieties to irrigation and fertilizer gradient) Range Mgmt. \& Agroforestry. 37(2) (2016) : 201-206.

[6] V.Sadras, O. M. Mahadevan, P.K. Zwer, (Oat phenotypes for drought adaptation and yield poteneal. Field Crops Res. 212 (2017) :135-144.

[7] S. A.Eberhart, W. A.Russell, (Stability parameters for comparing varieties) Crop Sci. 6 (1966) : 36-40.

[8] R. Dogan, O. Kacar,O.E.Goksu, N. Azkan, (Evaluation of triticale genotypes in terms of yield stability for the Southern Marmara region) Notulae Botanicae Horti Agrobotanici Cluj-Napoca, 39(2) (2011):249-253.

[9] احمد عبد الجو اد احمد وارشد ذنون النعيمي، (تقدير المعالم الور اثية وتحليل الاستقر ارية لمدخلات من الحنطة الخثنة - 37: مجلة علوم الر/فدبن ، 22 (1) (2011) (Triticum durum (Desf.)

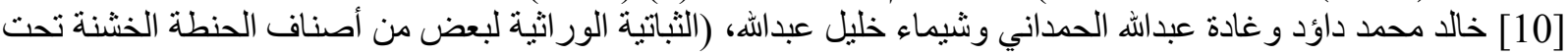

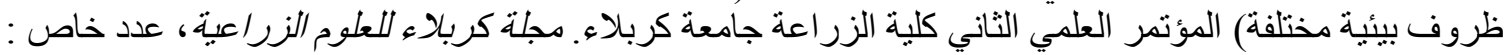

$$
\text { .2012) } 470-461
$$

[11] ، نمام بهرام إسماعيل ومحمد يوسف الفهادي، (الاستقر ار المظهري لصفات الحاصل ومكوناته و النوعية لسلالات مدخلة

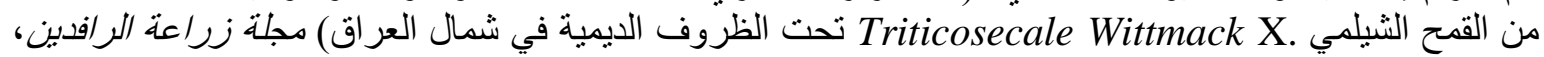

$$
\text { . } 40 \text { ملحق (1) (2012) : } 18 \text { : } 18
$$

[12] M.A. Abd EL-Shafi, E.M.S Ghelth, A.A Abd EL-Mohsen, H.S Suleiman, (Stability analysis and correlations among different stability parameters for grain yield in bread wheat). Sci. Agri.6(3) (2014) :135-140.

$$
\begin{aligned}
& \text { [13] عبد الكريم لقمس وبكور فيصل ومولود ماجد، (التداخل الور اثي البيئي وثباتية الغلة لطرز وسلالات مبشرة من القمح }
\end{aligned}
$$

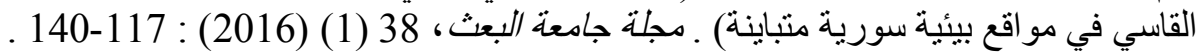

[14] F. Y.Baktash, (Genotypic stability for some bread wheat pure line) . The Iraqi Journal of Agricultural Sciences . 74: (Special Issue) (2016): 52-47.

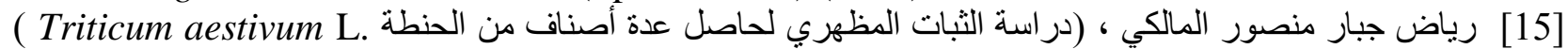

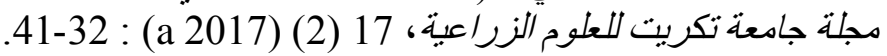

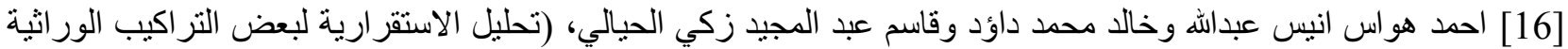
من حنطة الخبز (Triticum aestivum L.

[17] بولص خولي و هبة محمد منصور، (التغاير الور اثي X البيئي وتحليل الثباتية لبعض الطرز الور اثثية من القمح الطري

4riticum aestivum L. سلسلة العلوم البيولوجية، 40(4) (2018) :79 - 93 ـ 


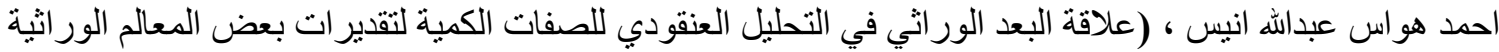

لتهجينات تبادلية من حنطة الخبز . Triticum aestivum L) الدجلة الدصرية للعلوم التطبيقية، 30 (2) (2015)

.151-130:

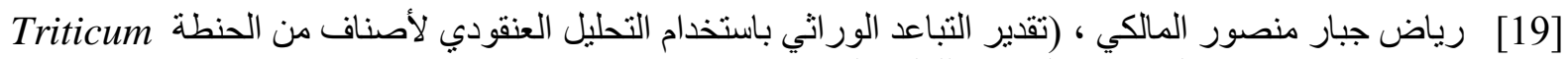

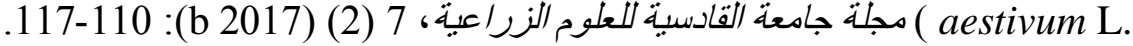

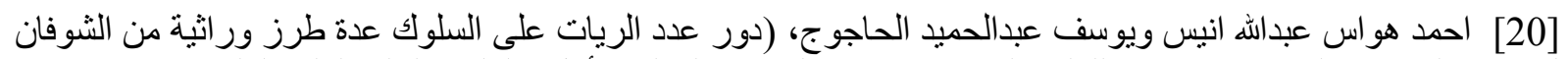

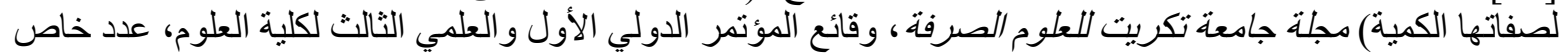

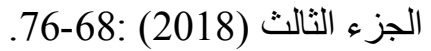

[21] جليل سباهي العابدي ، (دليل أستخدام الأسمدة الكيمياوية و العضوية في العراق). نشرة وزارة الزر اعة العر اقية (2011). [22] ارول محسن أنور ولي 2014. تأثثر المواقع ومعدلات البذار في الصفات الفسلجية والحاصل لأصناف من الشوفان (Avena sativa L.)

[23] H.Thomas, (The growth response to weather of simulator vegetation swards of a single genotype of lolium perenne) J. Agri. Sci. Camb. 84 (1975): 333 - 343.

[24] K.M. D Al-Zubaidy , M. A. H. Al-Falahy, ( Principle and Procedures of Statistics and Experimental Design). Duhok University Press , Iraq (2016).

[25] خالد محمد داؤد الزبيدي وخالد خليل أحمد الجبوري، (تصميم وتحليل التجارب الور اثية). دار الوضاح للنشر، المملكة الاردنية - عمان، مكتبة دجلة للطباعة و النشر والتوزيع، جمهورية العراق - بغداد (2016). 